\title{
AMB EL COR AL PAPER. HISTÒRIA I TEORIA DE LES CARTES D'AMOR. Jiménez Sureda's, Montserrat, Servei de Publicacions de la Universitat Autònoma de Barcelona, Bellaterra, 2020, (525 pages)
}

This review appraises Amb el cor al paper. Història i teoria de les cartes d'amor by historian Montserrat Jiménez Sureda, an extensive analysis of missives throughout history. Montserrat Jiménez Sureda is a scholar in Modern and Contemporary History and currently works at Universitat Autònoma de Barcelona.

This book is based on a collection of thoughts gathered throughout the process of analytical reading and comprehensive studying of an immense amount of letters. This is not a light-hearted book that delves into only love, but it anchors on what it means to portray love in letters, regardless of whom may be writing.

The book is a unique scope into uncharted territory. It strives to reveal how love appears represented in the words of some of the most celebrated scientists, spiritual leaders, entertainers, authors and thought-provoking thinkers and philosophers and social scientists throughout the centuries. The review will be an overview of the practicality of this book for readers, whichever their areas of expertise may be.

Jiménez Sureda mentions the huge importance this has to the field of epistolography, especially when thinking about the amount of institutionalized documentation and analysis related to modern letters documented, classified and accessible is albeit insufficient for educational purposes.

This is one of the main reasons for developing this combination of thoughts and factual information which enlists, strengthens and amplifies its presence in historical studies and analysis.

When entertaining love letters, one must not shy away from questioning the meaning of love itself and how it is portrayed in each case, as well as remembering romantic love is not the only one in this book.

This is an essential book that helps picture communication in a broad spectrum, spanning hundreds of years of thousands of written documents which revise some of the most well-known scientists, authors, philosophers, artists and holy figures in history, as well as personal information and experiences from the author herself.

It has an elaborate bibliography that 
spans a multiplicity of arts fields and develops the idea of love letters as a form of artistic expression which strives for their recognition to be understood as a portrayal of human endeavours, personal accounts of historical turning points and understanding an angle on the reality the authors live.

The review will be an account of the book's organization, as well as reflections and impressions regarding the author's content and style. The book is comprises four main parts, as well as an Index and References, as so:

Index

1. Greeting

2. Body

3. Farewell

4. Postscript

References

While the Greeting, Farewell and Postscript are roughly around fifteen pages each, the Body is divided into one hundred three chapters, amounting to a total of four hundred thirty pages. The Body is the primary source of information and theoretical contents.

It is important to notice it is structured the same way a letter would be composed. It is not shy of evoking the author's opinion, her beliefs are clearly visible within its pages. It outlines the basic issues tackled and explained in detail with the soul purpose of showing the process with which she has reached to the conclusions expressed throughout the text.

It is important to focus on how this book is written in order to understand how its reading should be managed. Square brackets are used amply to convey thoughts, opinions, experiences and beliefs in the form of short outbursts of commentary which can be omitted if need be.

Nonetheless, a brief read of those notes will aid the understanding of some of the contents in each chapter. These brackets are brief, colourful insights into what was being thought of when writing the chapter at hand.

When writing a love letter, a combination of emotional and factual content presses through the confines of the papers on which they are written. It is evident to suggest that this is a compendium of personal angles and views, epistemologically classified and whose primary focus is to enlighten the reader, as though it were communicating a series of semiotic imbrications to social, cultural and technological changes. These are contemplated synchronically, as well as diachronically with the help from these notes, with the soul purpose of showering the receiver with

the context one so direly needs in order to understand the context of the letter being analysed properly.

Jiménez Sureda's book might easily be a school book. The amount of information it contains begs for more analysis, as well as vast amounts of general knowledge and understanding.

When one takes up this book, the mind process must be of uncovering a new way of looking at historical truth, as well as anecdotes designed to lighten the mood, enriched with a flow of humorous, cutting-edge wit. Jiménez Sureda's mastery of the art of unravelling, developing and aiding the proper understanding of this discipline shows what thorough analysis is. Above all, she is a quality professor, as well as a prolific writer who has thrived where others have barely scratched the surface of their topics. Still, despite the stylish and personal approach to her writing, it is an extreme contrast that some might find difficult to understand or cope with. This book is, after all, a book in a letter's skeleton. It is a mirror image of what a letter should entail, with all its thoughts, impulsive emotional responses, brief flashbacks and footnotes that further elaborate how one gets to certain hypotheses regarding the writing style. The similarities with how 
one explains a story of what has been seen and how the mind connects thoughts is clear, and it feels natural, organic and much like the chaotic order with which our minds work on a daily basis, sorting out information and clarifying any underlying doubts we may have or empty spaces of knowledge we fill in with parallel situations we have experienced or creating metaphors so as to remember, albeit rather ironically, what ideas are being developed.

Although it is certainly a challenge, given the chance this book's contents develops in the same way two people would talk about personal experience how letters are a labour of love. They are based on the survival of one's thoughts within an anthrosphere that is the human psyche, captured on a bridge connecting social and personal revelations of oneself and how the World is emotionally and physically perceived and conducted.

The lessons learnt from this book are clear from the start, and you develop a keen desire to understand it and comprehend its value, not only as a collection of letters, but a collection of thoughts on the topic of letters. It is a topic you would have otherwise ignored and elicited as irrelevant contents in the fabric of society. A letter essentially unmasks the fear one feels when remembering they might leave thoughts unsaid, and one of the positive aspects of this book is precisely doing the opposite. It exposes them in plain sight, making them accessible to everyone and useful for anything.

Eric Hall Bordas Universitat Autònoma de Barcelona 